\title{
Perceived Self-Efficacy and Academic Achievement among Jordanian Students
}

\author{
Adnan Yousef Atoum ${ }^{1 *}$ and Abdolatif Al-Momani ${ }^{2}$ \\ ${ }^{1}$ Department of Counseling and Educational Psychology, Yarmouk University, Jordan \\ ${ }^{2}$ Department of Education, AL Balqa University, Jordan
}

Submission: July 20, 2018; Published: August 22, 2018

*Corresponding author: Adnan Yousef Atoum, Department of Counseling and Educational Psychology, Yarmouk University, Jordan, Email: atoumadnan@gmail.com

\begin{abstract}
The current study aimed at exploring the relationship between perceived self-efficacy and academic achievement among a sample of Jordanian secondary stage students through identifying the levels of perceived self-efficacy among students and identifying the effect of gender and academic achievement on self-efficacy. To achieve the study aims, the researchers applied the perceived self-efficacy scale on (356) secondary stage students and collected information on students' gender and academic achievement. The results of the study showed that the majority of students hold a moderate level of perceived self-efficacy in terms of the total score and in all domains scores of the scale. Also, the results showed a significant effect of academic achievement on perceived self-efficacy in favor of higher achievement students. In addition, the results showed no significant effect for gender or the interaction of academic achievement and gender on perceived self-efficacy. The results were discussed in terms of developmental and social aspects of the sample.
\end{abstract}

Keywords: Self-efficacy; Educators; Positive social interaction; Social reinforcement; Psychological processes

\section{Introduction}

Awareness of one's self dictates behavior, beliefs about abilities, task achievements and anticipation of success or failure. Bandura [1] has originally believed that self-efficacy mediate the relationship between an individual belief in terms of success or failure and actual behavior when performing a particular task. Self-efficacy is defined as the beliefs about individuals' capabilities to produce designated levels of performance that exercise influence over events or tasks that affect their lives [2]. Self-efficacy beliefs determine how someone feels, thinks, and behave. Educators often note how strong sense of efficacy may affect students' accomplishment and personal well-being. Students with high levels of selfefficacy are more likely to be certain about their capabilities when encountered by difficult tasks because they see that as a challenge rather than a way to avoid such difficult situations.

However, perceived self-efficacy can either enhance students' capabilities or decrease them. Those who have strong perceived self-efficacy will be able to analyze their problems and reach better solutions while those with low perceived self-efficacy will have doubts about their abilities and avoid initiating successful solutions especially in difficult situations [3]. This concept implies that self-efficacy is learned and can develop over age through positive social interaction and proper social reinforcement [4-5]. Bandura [6] stated that most of the research conducted showed that self-beliefs of efficacy affect human functioning on four major psychological processes. First, most human behavior is regulated by forethought embodying valued goals because personal goals are influenced by self-appraisal of capabilities. Second, self-efficacy plays a major role in the self-regulation of motivation because most human motivation is cognitively generated and forms beliefs about what they think they can do. Third, highly perceived self-efficacy affect people's beliefs in their coping capabilities and how much stress or anxiety they experience in threatening or difficult situations. Finally, highly perceived self-efficacy enables individuals to create beneficial environments and choose the individuals whom they can exercise some control during social interaction. Therefore, beliefs of personal efficacy can shape the course of social interaction and the types of activities and environments people choose.

Bandura [2] also identified several sources of self-efficacy. The first and strongest source stems from mastery experiences since successes build a robust belief in one's personal efficacy and failures undermine it. The second source stems from modeling since seeing people similar to oneself succeed by sustained effort raises one's beliefs that one also has similar capabilities and can succeed; similarly, observing others fail regardless of high effort lowers one's judgments of their own 
efficacy and undermines their efforts. Social persuasion is a third source of strengthening people's beliefs that they have what it takes to succeed. Students normally will do better if they are persuaded verbally that they possess certain capabilities in a particular task and are likely to perform better than students who have self doubt and focus on their personal deficiencies when facing a new task. The last source of successful efficacy comes from individuals' positive appraisals and self-improvement because those who have positive selfefficacy can structure situations that bring success and avoid placing themselves in situations where they may fail. Schunk $[7,8]$ found that self-efficacy research is viewed in domains relevant to education and several studies have addressed cognitive skills, social skills, motor skills, and career choices and have shown that self-efficacy is an important construct that helps to explain students' learning and performance of academic achievement. Such studies also have identified variables that are associated with educational contexts and that signal to students how well they are achieving or making progress in learning.

Marat [9] indicated that self-efficacy is viewed as a multidimensional construct that shares a reciprocal relationship with various determinants of learning and academic achievement. These determinants included motivation, strategies, cognitive strategies, resource management, self-regulated learning, meeting others' expectations, and self-assertiveness. Several studies revealed that students with highly self-efficacy capabilities showed better abilities in solving difficult tasks, more initiatives, less risk taking, more persistent, ambition and more emotional or social stabilities [9-12]. Other studies have shown a positive relationship between students' self-efficacy capabilities and academic achievements among school and university students; those who have higher perceived self-efficacy usually have better academic achievement [13-16]. Few studies showed that there was no significant relationship between perceived self-efficacy and academic achievement [4,17-19].

\section{The present problem}

Students with high self-efficacy capabilities are considered better in solving problems, work harder on difficult tasks, face more initiatives, take less risk, and show signs of persistent emotional and social stabilities. Most of the previous research has shown that perceived self-efficacy is an important factor that helps to explain students' learning and performance of academic achievement in Western cultures. Furthermore, academic achievement could be a determinant of self-efficacy, therefore, the present study aim at exploring the effect of academic achievement and students' gender on perceived selfefficacy among a sample of Jordanian secondary stage students. Also, the present study will attempt to identify the levels of perceived self-efficacy among students. In other words, the present study will answer the following questions: a. What is the level of perceived self-efficacy among a sample of Jordanian secondary stage students?

b. What is the effect of academic achievement and student's gender on perceived self-efficacy scores among a sample of Jordanian secondary stage students?"

\section{Significance of the study}

The significance of present study stems from the fact that it explores the relationship between self-efficacy capabilities and students learning and academic achievement. It brings more attention to the self-efficacy as a construct which shares a reciprocal relationship with various determinants of learning and academic achievement. Regardless of the many international studies on the topic, the authors have not found any direct studies on the relationship between perceived selfefficacy and academic achievement among school students at the Jordanian or Arabic regional level. Some local studies have attempted to study the impact of perceived self-efficacy on various factors such as depression and anxiety [20], moral development [21], need for achievement and adjustment [22], and locus of control and adjustment strategies [23]. Therefore, the present study will explore this relationship among a Jordanian sample and put some recommendations to teachers based on the results.

\section{Operational definition of terms}

Perceived Self-Efficacy: Students' estimation of their expectation towards abilities as measured by the perceived self-efficacy scale.

Academic Achievement: Students' CGPA at the End of the previous year based on school records.

\section{Method}

\section{Population and sample}

The population consisted of all secondary stage students enrolling in the 1st Irbid directorates of education in Jordan that were estimated at 7968 students (4090 males and 3878 females). The sample consisted of 356 students ( 210 males and 155 females) and was chosen randomly using sections in various schools as a unit of assignment.

\section{Study instrument}

To achieve the present study goals, the researchers adopted A Jordanian version of Perceived Self-Efficacy Scale developed by Al-Saqer in 2005 [21]. The scale consisted of 70 items distributed among nine domains (emotional, social, behavioral, self-confidence, confidence among others, persistent, cognitive, academic, and moral). Students rated each item using a 4-point Likert type scale ranging from 4-1 where (4) represents a high perceived self-efficacy and (1) represents a low perceived selfefficacy. 
Validity of the scale: The original Jordanian scale was validated through construct and

content validity procedures. To re-ensure the validity of scale, the researchers presented the original scales to 10 psychologists in Jordan. Proper changes were made to ensure good content validity based on agreements of $80 \%$ of judges.

Reliability of the scale: The original Jordanian scale was tested to be reliable through test-

retest method. However, the present researchers have ensured more reliability measures by distributing the scale to an independent sample of students (35 students) from the same population. Alpha score was (.91) for the whole scale, and scores ranged from .82 to .90 to all nine domains of the scale.

\section{Study procedures}

The scale was distributed directly by one of the researchers to the sample in groups, where each section chosen was treated as a group and each group ranged from 25-30 students. The researcher explained the purpose of the study and gave them instructions in how to rate each item in the scale. The researcher also gave one example on the blackboard in order to help the students understand their task. The researcher answered any questions raised by the students and collected the scales from the students allowing an average of 35 minutes to complete the task. Students General CGPA for the year 20072008 was collected from school records. Gender of the students was decided in advance since all schools used were not mixed gender schools.

\section{Results}

The results of this study are presented according to the study questions.

\section{First}

To answer the first question regarding "What is the level of perceived self-efficacy among a sample of Jordanian secondary stage students?", frequencies, percentages, means, and standard deviations for students' ratings on the perceived selfefficacy scale are shown in (Table 1 ). Table 1 shows an overall mean of (2.71) and means for scale domains ranged from (2.42) to (2.81), which suggests a moderate level of perceived selfefficacy among the sample for the total score and among all domains of the scale. Frequencies and percentages showed that (346) out (356), with a percentage of (97.2\%), have scores on the total sore of the perceived self-efficacy scale in the moderate level. Percentages of the moderate levels for all domains scores of perceived self-efficacy scale ranged from (73-89\%). Results also showed that the highest scores on perceived self-efficacy came from the social domain with a means of (2.81) and least scores came from the cognitive domain with a means of (2.42).

Table 1: Levels, Frequencies, Percentages, Means and Standard Deviations of perceived general self-efficacy and domains.

\begin{tabular}{|c|c|c|c|c|c|c|}
\hline S. D. & Means & Per. \% & Freq. & Levels of & & Domains \\
\hline \multirow{3}{*}{0.25} & \multirow{3}{*}{2.78} & $14.30 \%$ & 51 & $(3-4)$ & High & \multirow{3}{*}{ Emotional } \\
\hline & & $85.70 \%$ & 305 & $(2-2.99)$ & Moderate & \\
\hline & & $0 \%$ & 0 & $(1-1.99)$ & Low & \\
\hline \multirow{3}{*}{0.3} & \multirow{3}{*}{2.81} & $24.7 \%$ & 88 & $(3-4)$ & High & \multirow{3}{*}{ Social } \\
\hline & & $75.30 \%$ & 268 & $(2-2.99)$ & Moderate & \\
\hline & & $0 \%$ & 0 & (1-1.99) & Low & \\
\hline \multirow{3}{*}{0.29} & \multirow{3}{*}{2.74} & $10.40 \%$ & 37 & $(3-4)$ & High & \multirow{3}{*}{ Behavioral } \\
\hline & & $89 \%$ & 317 & $(2-2.99)$ & Moderate & \\
\hline & & $6 \%$ & 2 & (1-1.99) & Low & \\
\hline \multirow{3}{*}{0.3} & \multirow{3}{*}{2.75} & $14.30 \%$ & 51 & $(3-4)$ & High & \multirow{3}{*}{ Self-Confidence } \\
\hline & & $83.70 \%$ & 298 & $(2-2.99)$ & Moderate & \\
\hline & & $2 \%$ & 7 & (1-1.99) & Low & \\
\hline \multirow{3}{*}{0.38} & \multirow{3}{*}{2.75} & $21.10 \%$ & 75 & $(3-4)$ & High & \multirow{3}{*}{$\begin{array}{l}\text { Confidence } \\
\text { among others }\end{array}$} \\
\hline & & $73 \%$ & 260 & $(2-2.99)$ & Moderate & \\
\hline & & $5.90 \%$ & 21 & (1-1.99) & Low & \\
\hline \multirow{3}{*}{0.33} & \multirow{3}{*}{2.69} & $12.90 \%$ & 46 & $(3-4)$ & High & \multirow{3}{*}{ Persistent } \\
\hline & & $84.30 \%$ & 300 & $(2-2.99)$ & Moderate & \\
\hline & & $2.80 \%$ & 10 & (1-1.99) & Low & \\
\hline \multirow{3}{*}{0.31} & \multirow{3}{*}{2.42} & $11.20 \%$ & 40 & $(3-4)$ & High & \multirow{3}{*}{ Cognitive } \\
\hline & & $86.80 \%$ & 309 & $(2-2.99)$ & Moderate & \\
\hline & & $2 \%$ & 7 & $(1-1.99)$ & Low & \\
\hline
\end{tabular}




\section{Trends in Technical \& Scientific Research}

\begin{tabular}{|c|c|c|c|c|c|c|}
\hline \multirow{3}{*}{0.32} & \multirow{3}{*}{2.71} & $11.80 \%$ & 42 & $(3-4)$ & High \\
\cline { 3 - 6 } & & $84.30 \%$ & 300 & $(2-2.99)$ & Moderate & Mow \\
\cline { 3 - 6 } & \multirow{3}{*}{0.15} & $3.90 \%$ & 14 & $(1-1.99)$ & High \\
\cline { 3 - 6 } & \multirow{3}{*}{2.71} & $2.80 \%$ & 10 & $(3-4)$ & Moderate & Lotal Score \\
\cline { 3 - 6 } & & $97.20 \%$ & 346 & $(2-2.99)$ & $(1-1.99)$ & Low \\
\hline
\end{tabular}

\section{Second}

To answer the second question regarding "What is the effect of academic achievement and student's gender on perceived self-efficacy scores among a sample of Jordanian secondary stage students?", means and standard deviations for total scores of perceived self-efficacy scale based on achievement and gender were observed as in (Table 2). The results in Table 2 showed that females means (2.72) were slightly higher on perceived self-efficacy than males (2.70), and high achievement students (2.73) have higher means than average achievement students (2.71) and low achievement students (2.67). Two-way analysis of variance (ANOVA) was used to test for statistical significant differences in perceived self-efficacy due to variation in academic achievement levels and students gender as in (Table 3).

Table 2: Means and standard deviations of Perceived self-efficacy total scores.

\begin{tabular}{|c|c|c|c|}
\hline Indep. Var. & Males & Females & Averages \\
\hline $\begin{array}{c}\text { High } \\
\text { Achievement }\end{array}$ & 2.71 & 2.75 & 2.73 \\
\cline { 2 - 4 } & 0.15 & 0.13 & 0.14 \\
\hline $\begin{array}{c}\text { Average } \\
\text { Achievement }\end{array}$ & 2.7 & 2.72 & 2.71 \\
\cline { 2 - 4 } & 0.17 & 0.15 & 0.16 \\
\hline $\begin{array}{c}\text { Low } \\
\text { Achievement }\end{array}$ & 2.67 & 2.67 & 2.67 \\
\hline \multirow{2}{*}{ Total Means } & 0.16 & 0.14 & 0.15 \\
\cline { 2 - 4 } & 2.7 & 2.72 & 2.71 \\
\hline
\end{tabular}

Table 3: The effect of academic Achievement and gender on perceived self-efficacy.

\begin{tabular}{|c|c|c|c|c|}
\hline Source of Variance & $\begin{array}{c}\text { Sum of } \\
\text { Squares }\end{array}$ & DF & F & Sig. Of F \\
\hline Academic Achievement & 0.2 & 2 & 4.41 & 0.013 \\
\hline Gender & 2.66 & 1 & 1.18 & 0.279 \\
\hline 2-way Interaction & 3.06 & 2 & 0.68 & 0.51 \\
\hline
\end{tabular}

Using analysis of variance Table 3 showed that academic achievement has a significant effect on perceived self-efficacy $\mathrm{F},(2,374),=4.41 \mathrm{p}<0.05$, while gender had no significant effect on perceived self-efficacy (F, 1, 374, =.1,18 p<NS), and no interaction effect between gender and academic achievement on perceived self-efficacy (F, 2, 374, =,68 $\mathrm{p}<\mathrm{NS}$ ). Post-Hoc comparisons (Scheffe) for different levels of academic achievement revealed a significant difference $(p<0.05)$ in perceived self-efficacy between high achievement level $(M=2.73)$ and low achievement level $(M=2.67)$. Also there was no significant difference in perceived self-efficacy between average achievement level $(M=2.71)$ and low and high achievement levels.

\section{Discussion}

Results of the first question revealed that secondary stage students achieved a moderate level of perceived selfefficacy scores on the total scale and all domains of the scale. These findings are consistent with student age and stage of development, and development theories would suggest that students should be at a moderate level of beliefs about their capabilities since more experiences and practices are still yet to be achieved before the majority of them can reach high levels of self-efficacy. Consistent with these findings, students at this age face lots of social and emotional problems, which may reflect on their thinking processes, and concentration levels, which in turn affect their self awareness of such capabilities of self-efficacy. Furthermore, some social and cultural factors regarding the strict socialization processes and limitations emerging from traditional Muslim society could contribute to explanation of these moderate levels of perceived self-efficacy during this stage of student's lives. Previous findings in similar contexts showed similar results. Al-Saqer [21] in a study on the relationship between self-efficacy and moral development and Al-Muhsin [22] on a study on the relationship between self-efficacy and need for achievement and adjustment showed moderate levels of self-efficacy among college students.

Results also showed a significant effect of academic achievement on self-efficacy among a sample of secondary stage Jordanian students. This result means that high academic achievement is an important factor in explaining perceived self-efficacy. Thus, it is logical to assume that high achievers produce better beliefs about their capabilities and ability to perform various tasks. High achievement obviously helps students in terms of how they feel, think, and behave in various life situations which in turn reflect positively on perceived selfefficacy. Most learning theories would support the previous findings because previous success experiences in academic achievement are expected to influence the way students feel about themselves and consequently they develop a sense of self confidence. It also help students positively evaluate various events in their lives and avoid negative effects due to difficult or failing experiences and eventually would increase their perceived self-efficacy. The previous finding on the effect of 
academic achievement on students' self-efficacy capabilities is consistent with the majority of the previous research on secondary and college stage students [13-16]. Results also showed no significant effect of gender and the interaction between gender and academic achievement on perceived selfefficacy. This suggests that self-efficacy capabilities or beliefs are possibly more influenced by strict social and emotional socialization processes for both males and females. This issue needs further investigation since there is some disagreement on the nature of the differences in perceived self-efficacy due to gender $[22,24]$.

Teachers are recommended to pay more attention to students' perceived self-efficacy and should recognize the relationship between self-efficacy and academic achievement. Perceived self-efficacy is an important construct that helps to explain students' learning and performance in general, and to recognize that both variables are associated with enhancing educational success [25-27]. The present findings require teachers to give more attention to lower achievers in order to avoid lower perceived self-efficacy or negative self evolution due to failure or expected difficulties in various academic tasks and to provide students with proper successful experiences that would enable students to avoid developing low selfefficacy. Teachers should also take advantage of students' high achievement or various experiences of mere success by directing and guiding them toward producing better beliefs about their capabilities and developing a high sense of efficacy toward themselves as a result of such successful experiences. Small successful experiences can be useful in strengthening students' attitudes and beliefs about themselves and their capabilities.

\section{References}

1. Bandura A (1977) Self-efficacy: Toward a unifying theory of behavioral change. Psychological Review 84(2): 191-215.

2. Bandura A (1994) Self-efficacy. In: Ramachaudran VS (Ed.), Encyclopedia of human behavior, New York, USA, 4: 71-81.

3. Bandura A, Wood R (1989) Effect of Perceived Controllability and performance standards Self-Regulation of Compels Decision Making. Journal of Personality and Social Psychology 56(5): 805-814.

4. Himanshu D, Harpal H, Kumar D (2017) A comparative study of general self-efficacy of University level swimmers. International Journal of Physical Education, Sports and Health 4(1): 65-67.

5. Atoum AY, Al-Shoboul R (2018) Emotional support and its relationship to Emotional intelligence. Advances in Social Sciences Research Journal 5(1): 7-16.

6. Bandura A (1998) Self-Efficacy. In: Fridman H (Ed). Encyclopedia of Mental Health. San Diego: Academic press. USA.

7. Schunk D (1986) Self-Efficacy and Skill development Influence of Task Strategies and Attribution. Journal of Educational Research 79(1): 238-244.

8. Schunk D (1989) Self-efficacy and achievement behaviors. Springer Netherlands 1(3): 173-208.
9. Marat D (2017) Secondary school students' self-efficacy in mathematics and achievement in diverse schools. Unpublished Doctoral Dissertation.

10. Bong M (1997) Congruence of Measurement Specificity on Relations Between Academic Self-Efficacy Effort and Achievement Indexes. (ERIC Document Reproduction Service, No. ED 411261).

11. Al-Zyate F (2011) Cognitive Psychology. Universities Publishing House, Cairo (In Arabic).

12. Almomani F, Theeb A (2016) The ambition level and its relation with perceived self-efficacy in light of certain variables among a sample of Jordanian students. International Journal of Asian Social Science 6(12): 683-687.

13. Schmitz Q Schwarzer R (2000) Self-Efficacy of teachers: Longitudinal data using a new questionnaire. Zeitschrift for padagogische psychologie 14(1): 2-25.

14. John L, Andrew M (2001) Self-Efficacy and Academic performance. Social Behavior and Personality: An International Journal 29(7): 687694.

15. John L, Andrew M (2004) Self-Efficacy, Self-Esteem and Their Impact on Academic performance. Social Behavior and Personality: An International Journal 32(3): 247-256.

16. Namok C (2005) Self-Efficacy and Self Concept as Predictors of college students Academic performance. Psychology in the Schools 42(2): 197205.

17. Rapoo B (2001) The Relationships Among High-School students Perceptions of Instructional practices, Self-Efficacy, and Academic Achievement in South Africa. Dissertation Abstracts International. A61(12) 4674.

18. Liu M, Hsieh P, Cho Y, Schallert D (2006) Middle school students' selfefficacy, attitudes, and achievement in a computer-enhanced problembased learning environment. Journal of Interactive Learning Research 17(3): 225-242.

19. Atoum Adnan, Alhattab L (2015) Predicting Internet Addiction and Its Relation to Social Support among High Basic Stage Students. Journal of Educational and Psychological Studies [JEPS] 9 (2): 312-324.

20. Hamdy N, Dawood N (2000) The relation between perceived selfefficacy and depression and anxiety among a sample of Jordanian college students. Dirasat, 27(1), 118-131 (In Arabic).

21. Al-Saqer T (2005) Moral development and perceived self-efficacy among a sample of Yarmouk University students. Unpublished Master Thesis, Yarmouk University, Jordan (In Arabic).

22. Al-Muhsin S (2006) Perceived self-efficacy, need for achievement, and adjustment among a sample of college of education students. Unpublished Master Thesis, Yarmouk University, Jordan (In Arabic).

23. Al-Shipool A (2005) Coping strategies and their effect on perceived self-efficacy and locus of control among upper basic school students. Unpublished Doctoral dissertation, Amman Arabic University (In Arabic).

24. Dwyer A, Cummings A (2001) Stress, Self-Efficacy, Social support and coping strategies in University Students. Canadian Journal of Counseling 35(3): 208-220.

25. Bandura A (1986) Social Foundation of Thought and Action, Engle wood Cliffs Prentice Hall. Abstract International 56 (4): 123-129.

26. Academic Press. (Reprinted in H. Friedman [Ed.], Encyclopedia of mental health. San Diego: Academic Press, 1998).

27. Cheng N, Westwood P (2007) Self-efficacy, Personal Worries, and School Achievement of Primary School Students in Hong Kong. The Asia Pacific-Education Research 16(2): 143-154. 
This work is licensed under Creative Commons Attribution 4.0 License DOI: 10.19080/TTSR.2018.03.555602
Your next submission with Juniper Publishers will reach you the below assets

- Quality Editorial service

- Swift Peer Review

- Reprints availability

- E-prints Service

- Manuscript Podcast for convenient understanding

- Global attainment for your research

- Manuscript accessibility in different formats

( Pdf, E-pub, Full Text, Audio)

- Unceasing customer service

Track the below URL for one-step submission https://juniperpublishers.com/online-submission.php 